\title{
Educação Permanente com Agentes Comunitários de Saúde: potencialidades de uma formação norteada pelo referencial da Educação Popular e Saúde
}

Danielly Maia de Queiroz ${ }^{(a)}$

Maria Rocineide Ferreira da Silva ${ }^{(b)}$

Lúcia Conde de Oliveira ${ }^{(c)}$

Queiroz DM, Silva MRF, Oliveira LC. Continuing Education for Community Health Agents: potentialities of an education guided by the framework of Health and Popular Education. Interface (Botucatu). 2014;18 Supl 2:1199-1210.

In Family Health, the community health agent $(\mathrm{CHA})$ is the spokesperson for the care model; however, as he receives incipient education, continuing education must bridge gaps in his work. This study aimed to indicate the steps of the learning process experienced with $\mathrm{CHA}$ in the city of Pacoti (Northeastern Brazil): a proposed modus operandi of an education founded on the framework of Health and Popular Education. This is a qualitative study of the type "action research" involving $24 \mathrm{CHA}$. Eight workshops for shared knowledge construction were held. Based on the choice of themes, on the unveiling of common challenges among peers and on the proposals for overcoming them, causing destabilization of previously consolidated knowledge, it became evident that Health and Popular Education can break with the hegemonic alienating logic, inviting individuals to take risks on new ways of producing health.

Keywords: Community Health Agents. Human resources education. Family Health. Popular education. Continuing education.
Na Saúde da Família, o Agente Comunitário de Saúde (ACS) é porta-voz do modelo de atenção que se implementa; todavia, como recebe capacitações incipientes, é mister a educação permanente suprir gradativamente lacunas identificadas no seu cotidiano de trabalho. Objetivou-se indicar os passos do processo pedagógico vivenciado com os ACSs no município de Pacoti - CE, Brasil, proposta de modus operandi de uma formação alicerçada no referencial da Educação Popular e Saúde (EPS). Tratase de uma pesquisa qualitativa, do tipo pesquisa-ação, realizada com 24 ACSs. Promoveram-se oito oficinas de construção compartilhada do conhecimento. Desde a escolha dos temas, ao desvelamento de desafios comuns entre os pares e proposições de superação, provocando a desestabilização de conhecimentos previamente consolidados, evidenciou-se quão potente é a EPS para romper com uma lógica hegemônica alienante, instigando os sujeitos a se arriscarem em novas maneiras de produzir saúde.

Palavras-chave: Agentes Comunitários de Saúde. Formação de recursos humanos. Saúde da Família. Educação Popular. Educação permanente.

\footnotetext{
(a) Mestranda em Saúde Coletiva, Universidade Estadual do Ceará. Av. Contorno Oeste, 57, Nova Metrópole. Caucaia, CE, Brasil. 61658-040. daniellymaia@yahoo.

(b) Curso de Enfermagem Universidade Estadual do Ceará (UECE).

Fortaleza, CE, Brasil. rocineideferreira@gmail.

(c) Curso de Serviço Social, UECE. Fortaleza, CE, Brasil.conde.lucia@ gmail.com
} 


\section{Introdução}

A Saúde da Família é um campo de saberes e práticas escolhido como estratégia de reorientação do modelo de atenção em saúde no Brasil' ${ }^{1}$. Orienta-se pelos princípios do Sistema Único de Saúde de universalidade, integralidade, equidade e participação social. Expressa ainda alguns fundamentos e diretrizes: planejamento e desenvolvimento de ações com impacto nos condicionantes e determinantes do processo saúde-doença de indivíduos e coletividades; acessibilidade e acolhimento; longitudinalidade do cuidado; gestão do cuidado integral; e estímulo à participação dos usuários².

Para tanto, as equipes de Saúde da Família (EqSF), compostas por agentes comunitários de saúde (ACS), enfermeiros, técnicos de enfermagem, médicos, odontólogos, auxiliares e/ou técnicos de saúde bucal, buscam contemplar, em seu processo de trabalho, algumas características, tais como organização da agenda de trabalho, pautada nas necessidades de saúde da população sob sua responsabilidade, realização de ações educativas, que fomentem a autonomia dos sujeitos, e ainda desenvolvimento de ações intersetoriais².

O modo de produzir saúde, no contexto da Estratégia Saúde da Família, precisa ser repensado. Essa iniciativa exige a ruptura com o modo de fazer centrado em procedimentos técnicos, incorporandose o modo de produção de cuidados. Para tanto, é necessário lançar mão de "dispositivos capazes de provocar a quebra de certezas construídas ao longo do processo histórico"3 (p. 10). Assim, ao se refletir sobre essas certezas, é possível arriscar novas formas de fazer saúde ${ }^{3}$.

Em razão desse desafio, o ACS cumpre papel estratégico junto à EqSF, por ser considerado "o elo inicial do trabalho, aquele que recebe e encaminha as demandas individuais e coletivas da comunidade, bem como aquele que será o principal porta-voz do modelo de saúde que se implementa", como afirmam Malfitano e Lopes ${ }^{4}$ (p. 366). Dentre suas atribuições, cabe-Ihe desenvolver atividades de promoção da saúde, prevenção de doenças e vigilância à saúde, por meio de visitas domiciliares e de ações educativas a serem implementadas junto às famílias acompanhadas².

Investir na formação técnica e na valorização desses trabalhadores é sinônimo de fortalecimento da Estratégia Saúde da Família. Todavia, a ausência de proposições de processos pedagógicos, pautados em referenciais que possibilitem aprendizagem significativa e que reúnam qualidade ao trabalho desempenhado pelos ACSs, pode infligir perdas no papel assumido por essa política pública. O fato de não discutir nem saber lidar com problemas identificados no cotidiano de trabalho pode ensejar angústia, fragilizando o acompanhamento e a orientação de famílias sob sua responsabilidade; e ainda contribuir com a manutenção de práticas equivocadas, pautadas no biologicismo e na "medicalização".

As propostas educativas ascendentes, indutoras de mudança no cotidiano dos serviços e que levem em consideração a micropolítica dos contextos locais, estão em disputa no cenário político das esferas de governo, permeado de contradições. Por exemplo, mesmo com os avanços do processo de descentralização, o Ministério da Saúde ainda é o responsável por estabelecer os "conteúdos programáticos" do curso de formação técnica do ACS que vêm sendo desenvolvidos nos estados.

No Ceará, a Escola de Saúde Pública programou a formação técnica em três etapas. A primeira contemplou todos os ACSs do estado, a segunda, apenas uma parcela, e a terceira não aconteceu. Uma pesquisa avaliativa da primeira etapa dessa formação apontou para a complexidade do trabalho proposto para os ACSs e o excesso de atribuições que não podem ser aprendidas por meio de formações pontuais 5 . Pelo contrário, requerem educação permanente protagonizada não só pelos ACSs, mas por toda a equipe de Saúde da Família.

Tratando-se do processo de trabalho do ACS, uma das suas atribuições se refere à realização de ações de Educação em Saúde, ações estas que precisam ser questionadas quanto aos referenciais e às racionalidades que as norteiam. Apesar de iniciativas de mudança, conforme se percebe, a Educação em Saúde, inserida nos processos de formação de profissionais e nas relações firmadas entre estes e os usuários do sistema, ainda está arraigada em uma racionalidade capturada pela razão iluminista predominante na produção do conhecimento da ciência moderna e no jeito de organizar os serviços ${ }^{6}$.

Como proposto, a educação permanente se faz necessária, sobretudo como vistas a superar gradativamente as lacunas das capacitações ofertadas aos $\mathrm{ACSs}^{7}$, aprimorando, assim, o trabalho executado por esses membros híbridos e polifônicos da EqSF${ }^{8}$. 
Para tanto, em face da dinâmica das atividades dos ACSs e das atribuições assumidas por eles, a Educação Popular mostra-se como potente ferramenta pedagógica, porquanto os saberes dos sujeitos são valorizados, não se reproduzindo a passividade usual dos processos pedagógicos tradicionais ${ }^{9}$, fomentando novas formas de produção de cuidados junto às famílias acompanhadas.

Com o emprego da Educação Popular e Saúde (EPS) como referencial, torna-se possível promover processos formativos que tenham impacto na qualidade do trabalho desenvolvido pelos ACSs. Somamse, ainda, a valorização dos seus saberes prévios, o fomento à troca de experiências, a identificação de situações-limite, para melhorar o planejamento das ações, a ampliação de visão de mundo, o aumento da autoestima e o convite ao protagonismo, à emancipação e à liberdade.

Ante o exposto, este estudo se propõe responder ao seguinte questionamento: Quais as potencialidades evidenciadas ao se desenvolver uma estratégia de educação permanente com ACS, norteando-se pelo referencial da EPS? Para tanto, objetiva-se indicar os passos de um processo pedagógico vivenciado com ACS em um município de uma região serrana cearense.

Sob norte do referencial citado, foram propostas oficinas de construção compartilhada do conhecimento, baseadas em problemáticas previamente escolhidas pelos sujeitos, propiciando um ambiente dialógico e formativo, que favoreceu discussões, trocas de experiências e reflexões acerca das suas concepções, do seu saber-fazer e de iniciativas necessárias ao cenário de práticas da Saúde da Família.

\section{Educação Popular e Saúde}

A Educação Popular traz em sua concepção a valorização do saber do outro e o conhecimento como um processo de construção coletiva. Suas raízes se encontram em Paulo Freire, notável educador brasileiro que, em suas obras, posiciona a educação como instrumento de conscientização, libertação e transformação ${ }^{10}$.

Em "Pedagogia do Oprimido", Freire destaca a necessidade de superar a relação desigual entre educador e educando, e propõe diálogo e respeito mútuo como ferramentas indispensáveis para o estabelecimento de relações dialógicas ${ }^{11}$. Em "Pedagogia da Autonomia", ele considera como elementos essenciais da prática educativa o respeito aos saberes dos educandos, criticidade, bom senso, humildade e apreensão da realidade. O educador precisa ter convicção de que a mudança é possível e compromisso com a educação como prática libertadora pautada na ética universal do ser humano ${ }^{12}$.

As primeiras experiências de Educação Popular na saúde se reportam ao início da década de 1970, período marcado por experiências alternativas de saúde, reestruturação das comunidades eclesiais de base e ressurgimento de movimentos sociais de luta contra a ditadura militar brasileira ${ }^{10}$.

Nesse contexto de lutas pela democratização da sociedade, são gestados vários movimentos, entre estes, o movimento pela Reforma Sanitária Brasileira, o qual traz uma proposta de transformação social pensada a partir da questão da saúde. Condicionantes históricos marcam esse processo como uma revolução passiva, ou seja, com mudanças, mas muitas conservações ${ }^{13}$. Isso reitera a necessidade da Educação Popular na saúde como uma estratégia para favorecer a participação popular e rearticular o segmento social que ficou mais frágil nesse movimento.

A Educação Popular propicia a reorientação das práticas dos serviços. Desse modo, contribui para a superação do seu caráter restritamente biologicista, configurando-se como um instrumento para estabelecer uma atenção mais integral e centrada no usuário. Por meio de processos pedagógicos mais horizontais, pautados no diálogo e na troca de saberes, ela fomenta maneiras coletivas de aprendizado que promovam o crescimento da capacidade de análise crítica dos sujeitos sobre a realidade na qual se encontram, para tornar possível o aperfeiçoamento de estratégias de luta e enfrentamento9.

Tem-se como exemplo de proposta metodológica, baseada no referencial pedagógico da EPS, a oficina de construção compartilhada do conhecimento, uma proposta que parte da realidade local, valoriza a criatividade e o uso de múltiplas linguagens. E ainda se propõe desconstruir conceitos $\mathrm{e}$ valores, numa negociação de significados que reforcem o laço social estabelecido com suporte no aprendizado entre sujeitos ${ }^{14}$. 
Consoante mencionado, a EPS reconhece a dialogicidade e utiliza a problematização como método de compreensão da realidade, no intuito de ensejar processos de ação-reflexão-ação que apontem soluções efetivas de problemas desvelados no cotidiano ${ }^{15}$.

No contexto de produção de cuidados, a Educação Popular não deve significar uma atividade a mais a ser efetivada, e sim nortear ações que reorientem as práticas executadas. Com efeito, é considerada como instrumento de formulação de ações de saúde mais integrais e adequadas à vida da população, com vistas a fortalecer e reorientar práticas, saberes e lutas cotidianas 9 .

Reconhecer o "popular" do processo educativo na saúde é incorporar, de maneira implícita ou explícita, um projeto de libertação, emancipação, autonomia, cogestão, solidariedade, justiça e equidade, favorecendo o construto de sujeitos sociais ${ }^{16}$.

\section{Percurso metodológico}

O estudo foi realizado em Pacoti - Ceará, município de pequeno porte, localizado na região serrana cearense, o qual, de acordo com o Plano Diretor de Regionalização da Secretaria da Saúde do Estado do Ceará, pertence à Macrorregião de Fortaleza e é um dos oito municípios da Microrregião de Saúde de Baturité17.

Segundo dados disponíveis na Sala de Apoio à Gestão Estratégica do Ministério da Saúde ${ }^{18}$, Pacoti conta com uma população de 11.684 habitantes, possui cinco equipes de Saúde da Família - duas urbanas e três rurais -, conta com 27 ACSs e cobertura de 100\% da população pela Estratégia Saúde da Família. Em 2007, o município assinou o Termo de Compromisso de Gestão em conformidade com as diretrizes do Pacto pela Saúde 2006.

No estudo ora desenvolvido, de abordagem qualitativa, do tipo pesquisa-ação, pretende-se um exercício de práxis, porquanto se refere a uma ação alicerçada numa teoria e associada a uma estratégia ${ }^{19}$, não se admitindo trabalhar "sobre" os outros, mas necessariamente "com" os outros.

Esse referencial requer do pesquisador uma implicação pela estrutura social onde está inserido e, dialeticamente, acaba por implicar os outros por meio do seu olhar e ação singular no mundo. Nesse âmbito, a relação de uma das pesquisadoras com o objeto de estudo se deu mediante sua imersão na Saúde da Família de Pacoti - CE, como interna do curso de Enfermagem da Universidade Estadual do Ceará (UECE).

Ao longo dos quatro meses em que esteve inserida nesse cenário, ela pôde estabelecer uma relação de confiança com os ACSs e formar parcerias imprescindíveis para a elaboração deste estudo. Uma delas foi a aproximação junto ao sindicato dos ACSs do município, que facilitou o diálogo e o início do levantamento de situações-limite enfrentadas no cotidiano de trabalho. Da pesquisa participaram 24 agentes como sujeitos do estudo, ou seja, $89 \%$ do total vinculado ao município.

Segundo Barbier ${ }^{19}$, o método em pesquisa-ação dispõe das seguintes etapas: 1. identificação do problema e contratualização; 2. planejamento e ação; e 3. teorização, avaliação e publicação dos resultados.

Durante a imersão no território, algumas atividades implementadas pelas equipes de Saúde da Família foram acompanhadas e, ainda, em conversas com ACSs, apontamentos foram registrados no diário de campo. Essas anotações propiciaram a identificação do problema da inexistência de ações de educação permanente, no âmbito municipal, que contemplassem como sujeitos os ACSs. De acordo com o recomendado, é importante estar atento às reais necessidades identificadas pelo coletivo e não apenas fazer a oferta orientada por aquilo que profissionais externos julgam importante ${ }^{20}$.

Em consonância com tal afirmação, a contratualização da proposta de formação foi pautada em problemáticas eleitas pelos ACSs como prioritárias para o seu processo de trabalho. Nesse prisma, a escolha das situações-limite, enfrentadas por eles, ocorreu em uma das suas reuniões do sindicato. Houve visível receptividade, talvez pela falta, até então, de processos formativos baseados na escuta ativa do que eles consideravam como questões relevantes a serem abordadas.

Durante essa conversa com os ACSs, os problemas inventariados foram os seguintes: dificuldade em estabelecer relacionamentos interpessoais salutares, em virtude do estresse vivenciado no cotidiano de 
trabalho; escassez de ações de promoção da saúde, que deveriam ser prioridade na Saúde da Família; dificuldade no acompanhamento de usuários com doenças crônicas (hipertensos e diabéticos), por não saberem lidar com a falta de adesão ao tratamento proposto.

Foram planejadas e realizadas oficinas de construção compartilhada do conhecimento, balizadas pela Educação Popular e Saúde. Consideradas metodologia ativa e problematizadora do processo educativo, as oficinas possibilitam aos sujeitos a oportunidade de expressar pensamentos e experiências, num ato reflexivo de análise, julgamento e proposição de soluções de maneira coletiva. Trazem para o campo da discussão/reflexão problemáticas pertinentes à realidade vivida ${ }^{21}$.

Para nortear as discussões e os construtos do coletivo, durante as oficinas, alguns objetivos foram elaborados: 1 identificar formas potentes de estabelecimento de um bom relacionamento interpessoal; 2 entender as concepções sobre promoção da saúde; 3 propor estratégias para promover a saúde da população; e 4 identificar desafios e possibilidades de cuidado no acompanhamento de hipertensos e diabéticos.

Cada um desses objetivos foi trabalhado em duas oficinas. Uma para discussão e aprofundamento da situação-limite, colocada em pauta, e outra para elaboração e socialização dos materiais produzidos, fruto da construção coletiva realizada pelo grupo. No total, promoveram-se oito oficinas, e a média de participantes foi de 22 ACSs por oficina.

De posse do material sistematizado com apoio nas oficinas, passou-se a organizá-lo por temáticas e a avaliá-lo com suporte no referencial de análise do discurso do sujeito coletivo ${ }^{22}$, sendo elaborados textos-síntese e painéis.

Negociou-se com a gestão municipal e com as equipes de Saúde da Família a liberação de todos os ACSs interessados em participar do processo formativo, além do custeio de materiais utilizados durante as atividades. Os resultados foram socializados em reunião no município com a presença das equipes de Saúde da Família e da gestão municipal de saúde, representada pela coordenação da Atenção Básica.

Essa devolutiva trouxe à tona outras problemáticas enfrentadas como, por exemplo, dificuldade em realizar ações intersetoriais, vínculos trabalhistas fragilizados de algumas categorias profissionais e inexistência de uma política municipal de educação permanente. Além disso, reconheceu-se a necessidade de se discutir nas equipes propostas concretas que contemplassem ações de promoção da saúde. Esse momento também representou um convite público à gestão municipal e aos trabalhadores de saúde a se posicionarem igualmente como sujeitos de transformação da realidade na qual estavam inseridos.

Cabe ressaltar que este estudo é um recorte da pesquisa intitulada "Educação popular e promoção da saúde: estratégias para o fortalecimento da participação popular no contexto da Saúde da Família do Município de Pacoti - Ceará"(d), aprovada pelo Comitê de Ética em Pesquisa da Universidade Estadual do Ceará.

\section{Resultados e discussão}

Após as devidas negociações com a gestão municipal e as equipes de Saúde da Família, deu-se início às oficinas com os ACSs. Na primeira, estabeleceu-se um acordo de convivência, estipulando-se dias e horários, formação de equipes de acolhida e apresentação da proposta metodológica. Esta consistia em intercalar 
uma oficina de problematização e uma de elaboração de propostas de enfrentamento, com base na construção compartilhada do conhecimento.

Mediante a participação em dinâmicas contextualizadas, fortaleceram-se a interação e o trabalho mútuo; as dramatizações propiciaram expressar problemas vivenciados no cotidiano do trabalho; o uso do simbólico desvelou concepções, visões de mundo e afetos; e a elaboração de textos-síntese e painéis permitiu ancorar o conhecimento constituído e circulado durante os encontros.

Com a sistematização do processo vivenciado, buscou-se evidenciar as potencialidades da Educação Popular. Na experiência, destacaram-se os avanços e as questões impulsionadoras de mudança, e, assim, pôde-se delinear uma proposta de modus operandi para ações de educação permanente em outros cenários.

\section{Reflexões sobre relacionamentos interpessoais mais saudáveis}

Ao expressarem a dificuldade em estabelecer relacionamentos interpessoais salutares, fruto de situações estressantes do cotidiano de trabalho, os ACSs foram convidados pela pesquisadora a refletir sobre o que desencadeava esses sentimentos desgastantes.

Segundo as discussões, os entraves identificados diziam respeito à falta de diálogo na equipe, às relações ruidosas estabelecidas no "acompanhamento" de algumas famílias sob sua responsabilidade ou às situações conflitantes com a gestão municipal. Esses entraves ensejavam incômodos por vezes silenciados.

Contudo, ao socializarem tais situações, segundo se percebeu, os ACSs reconheciam a fortaleza do "encontro", identificando-se com o problema relatado pelo outro e compreendendo a presença de uma dimensão terapêutica protagonizada por eles no ato de falar e de ouvir atentamente.

Alguns demonstraram surpresa, pois apesar de trabalharem em um município pequeno e já terem certa organização da categoria por meio do sindicato, não se reuniam para tratar de problemas inerentes ao processo de trabalho. Isso suscitou o reconhecimento, nos próprios pares, da necessidade de constituírem uma rede de apoio entre si.

Motivados pelo desejo de mudança, diante da síntese de situações-limite que se desdobravam em relações interpessoais adoecedoras, construíram um painel com o que julgavam relevante para firmar relações mais salutares no dia a dia:

Necessidade de saber ouvir; estar aberto para o diálogo; romper com preconceitos; não negar que o estresse está presente no cotidiano; reconhecer que nas relações, o campo emocional e moral são por vezes afetados e que é possível contar com os colegas de trabalho e com o apoio institucional para enfrentar dificuldades ou incômodos disparados por situações consideradas estressantes. (Síntese do Painel "Estabelecendo relacionamentos interpessoais mais saudáveis" Coletivo de ACS de Pacoti)

Em face da postura assumida por eles, já nessas duas primeiras oficinas, pôde-se identificar sentimento de pertença, tão necessário para processos formativos pautados no protagonismo dos sujeitos, como o da Educação Popular. Por sua vez, a pesquisadora, ao assumir a posição de facilitadora ou mesmo apoiadora institucional, também pôde compartilhar desse sentimento de pertença.

Conforme ressaltado, a escolha intencional por esse tipo de formação se contrapõe à passividade usual dos processos formativos tradicionais ${ }^{9}$, permitindo troca de experiências e identificação de possibilidades de mudança no contexto no qual os sujeitos estão inseridos.

Optar por uma prática pedagógica libertadora admite certas qualidades ou virtudes imprescindíveis, tais como abertura ao novo, respeito aos outros, amorosidade, disponibilidade à mudança e persistência na luta ${ }^{12}$. Assim, convencida da importância dessas qualidades, a pesquisadora tentou estabelecer sua relação com os ACSs, reconhecendo a força propulsora existente nas propostas formativas norteadas pela Educação Popular e Saúde. 


\section{Concepções sobre promoção da saúde e sua práxis}

Tendo como ponto de partida a problemática da escassez de ações de promoção da saúde, as quais deveriam ser prioridade no contexto da Saúde da Família, buscou-se trabalhar nas quatro oficinas seguintes o alcance de dois objetivos. Primeiramente, entender as concepções dos ACSs sobre promoção da saúde e, em seguida, propor ao coletivo a enumeração de estratégias que contribuíssem com o fomento à promoção da saúde.

$\mathrm{Na}$ perspectiva de contribuir com a discussão e o aprofundamento do problema colocado em pauta, os ACSs foram convidados a construir o "Varal da Promoção da Saúde", com a formulação de respostas para o seguinte questionamento - o que é promoção da saúde? Em tarjetas com formato de peças de roupa, eles anotavam seus pontos de vista e, em seguida, penduravam no "Varal". Depois, as respostas eram lidas e discutidas pelo grupo.

Sobre o conceito de promoção da saúde, tem-se, então, o discurso-síntese, sistematizado a partir do "Varal da Promoção da Saúde":

É busca de qualidade de vida, tendo bons hábitos de alimentação e de higiene, praticar algum tipo de esporte, estar com a família reunida, ter uma moradia digna, paz interior, boa escola para os filhos, ter emprego. É desenvolver ações estratégicas para esclarecer a população sobre um conjunto de cuidados que devem ter para que tenham saúde, cuidados que podem ser individuais e coletivos; é promover grupos de apoio onde todos participem. É quando se tem acesso ao sistema de saúde local e assistência médica de qualidade. É ir ao encontro da população, tentar juntar, organizar, reivindicar seus direitos por melhores condições sanitárias perante os gestores. (Discurso-síntese "O que é promoção da saúde" - Coletivo de ACS de Pacoti)

Essas diversas concepções ratificam a afirmação segundo a qual o campo da promoção da saúde se encontra em elaboração, predominando uma polissemia de significados e conceitos ${ }^{23}$. Admitem-se desde ações voltadas aos indivíduos, suas famílias, condições de trabalho, renda, alimentação, estilos de vida e lazer, decorrentes de formulações de políticas públicas que incentivam escolhas mais saudáveis, a intervenções sustentadas pela intersetorialidade e pela participação social, voltadas para a luta pelo direito à saúde e por melhorias das condições de vida ${ }^{23}$.

Nessa ótica, o conceito de promoção da saúde, elaborado coletivamente pelos ACSs, dialoga tanto com a Política Nacional de Promoção da Saúde ${ }^{24}$, quanto com a Carta de Ottawa ${ }^{25}$. Está permeado por essas influências.

A Política Nacional de Promoção da Saúde fundamenta-se essencialmente no desenvolvimento de atitudes pessoais, tais como consumo de uma alimentação saudável, realização de atividade física, prevenção e controle do tabagismo e do uso abusivo de álcool, entre outras escolhas individuais, associadas a um estilo de vida saudáve ${ }^{24}$. Contudo, essa política é restrita, pois não enfatiza elementos decisivos para a determinação social do processo saúde-doença.

Já a Carta de Ottawa, documento fruto da primeira Conferência Internacional sobre Promoção da Saúde, ocorrida em 1986, reconhece a promoção da saúde como um processo de empoderamento da comunidade para melhorar sua qualidade de vida. Logo, não é responsabilidade exclusiva do setor de saúde, indo além do incentivo a um estilo de vida saudável. Essa carta de intenções propõe a reorientação dos serviços de atenção primária, com enfoque na promoção da saúde; reforça a ação comunitária por meio do fortalecimento da participação popular; sugere a criação de ambientes favoráveis e o desenvolvimento de habilidades pessoais assumidas na perspectiva intersetorial ${ }^{25}$.

Ao se analisar esses referenciais e compará-los com as iniciativas na realidade brasileira, admiti-se existir uma distância para a concretização da promoção da saúde na Saúde da Família. Desvelar essas concepções permite uma tomada de consciência, na perspectiva freiriana. Isso significa se mobilizar para a ação capaz de transformar o cotidiano dos serviços.

Em continuidade, com esteio nas interligações entre teoria e prática, e em face das possibilidades de atuação dos ACSs junto às suas equipes, lançou-se o seguinte questionamento: o que pode ser feito para promover a saúde da população? Nesse intuito, os ACSs elaboraram o painel intitulado "Práxis da Promoção da Saúde", conforme exposto sinteticamente. 
I - Saúde da Família como promotora intensiva da saúde: saber se expressar por meio do diálogo, sendo mais comunicativo, ganhando a confiança, o respeito e a amizade na construção efetiva de vínculos com as famílias; II - desenvolver um trabalho comunitário com simplicidade e humildade, formando grupos que possibilitem falar a linguagem do povo; III - reconhecer a limitação do modelo "medicalizante"; IV - pensar junto com a comunidade e com o poder público soluções para minimizar os fatores que submetem a risco a saúde da população; $V$ - articular-se com as demais políticas públicas, não carregando sozinhos toda a responsabilidade pela luta e garantia da saúde da população; e VI - solicitar aos gestores o cumprimento das ações relacionadas aos serviços de saúde (ex.: cumprimento da carga horária semanal exigida, disponibilidade de medicações receitadas, calendário sistemático de coleta de lixo, acesso à água tratada, etc.). (Síntese do Painel "Práxis da promoção da saúde" - Coletivo de ACS de Pacoti)

Na percepção do coletivo de ACS, a Estratégia Saúde da Família constitui lócus privilegiado para a promoção da saúde. Contudo, estudos já apontam que o exercício de práxis não configura tarefa fácil, sendo necessário o fortalecimento da capacidade individual e coletiva para lidar com a multiplicidade dos condicionantes e determinantes do processo saúde-doença e contrapor-se à crescente "medicalização" da vida social26,27.

Ainda, conforme as mesmas fontes, o fomento à autonomia, à concretização de políticas públicas intersetoriais, à interlocução entre saberes científico e popular, dentre outras iniciativas, consiste em etapas importantes para a consolidação da promoção da saúde ${ }^{26,27}$.

Dessa maneira, as equipes precisam desviar sua atenção da perspectiva estrita do adoecimento $\mathrm{e}$ dos sintomas para o acolhimento das histórias de vida da população, numa mudança de atitude que permita aguçar a visão para as condições de vida em que se encontram as famílias acompanhadas. Portanto, urge deslocar o labor centrado em procedimentos para um processo de trabalho centrado no usuário e em suas necessidades reais de saúde 2 .

De acordo com Pedrosa ${ }^{23}$, a maior expressão da promoção da saúde é “o desenvolvimento da capacidade de aprendizagem política e de enfrentamento criativo dos problemas que fazem parte da vida" (p. 626). Na ótica do autor, para o processo de institucionalização da promoção da saúde é mister uma parceria com a sociedade civil, denominada, por ele, de a "micropolítica do encontro". Assim, as avaliações das intervenções efetuadas nesse campo poderão se dar de forma compartilhada, já que a população é interlocutora desse processo ${ }^{23}$.

Ao constatarem a escassez de ações de promoção da saúde, os ACSs se permitiram discutir esse ponto nevrálgico, relacionado diretamente a funções assumidas por eles. Construir coletivamente uma concepção sobre promoção da saúde e dispor-se a elaborar um painel, considerando o que poderia ser implementado para dar vida à concepção delineada, foi um relevante exercício.

Em consonância com o propósito maior da Educação Popular e Saúde de ampliar a criticidade e delinear estratégias de luta e enfrentamento ${ }^{9}$, segundo foi possível perceber, as reflexões do coletivo de ACS propiciaram a abertura para a ressignificação do seu processo de trabalho, desestabilizando conhecimentos previamente consolidados e ampliando a visão de mundo desses articuladores comunitários, potentes promotores de saúde.

\section{Desafios e possibilidades de cuidado no acompanhamento longitudinal de hipertensos e diabéticos}

Nas duas últimas oficinas, a problemática em pauta relacionou-se às dificuldades enfrentadas no acompanhamento de usuários com hipertensão e diabetes. Os objetivos foram identificar junto ao coletivo de ACS desafios concernentes ao acompanhamento desses usuários e elencar possibilidades de cuidado favorecedoras de um acompanhamento longitudinal mais coerente com as necessidades apresentadas.

Para trazer à tona esses desafios, utilizou-se a "Dinâmica da Corda". Nesta, a cada problemática socializada pelos ACSs quanto à falta de adesão ao plano terapêutico, um nó era dado na corda. Ao 
final, a grande corda ficou cheia de nós e bem curta. Discutiu-se a importância da socialização dos desafios identificados no cotidiano, os quais, embora no início pareçam enormes e com possibilidade remota de superação, ao serem trazidos para o debate, evidencia-se a oportunidade de planejamento de ações para superá-los. Desse modo, encurta-se a distância entre problemática e proposta de resolução.

Nesse prisma, os participantes também foram convidados a realizar sociodramas para representar situações-limite do seu contexto de trabalho, e apontar possíveis soluções. Neste painel, a questão problematizadora formulada foi a seguinte: em razão das dificuldades enfrentadas pelos usuários hipertensos e diabéticos em aderir ao plano terapêutico, o que é possível fazer para potencializar o cuidado longitudinal? Tem-se, a seguir, parte desse construto coletivo, e nele sobressaem desafios e possibilidades dessa negociação terapêutica:

Desafios identificados: I - falta de aceitação quanto às limitações impostas pela situação de adoecimento; II - dificuldade na reeducação alimentar e difícil realização de atividade física em locais acidentados (ex.: ladeiras existentes nas localidades do município); III - falta de compromisso de alguns familiares; IV - falta de um grupo de apoio que fale a mesma linguagem e que possibilite a troca de experiências para o enfrentamento das privações cotidianas.

Possibilidades: I - antes de "orientar", é preciso "compreender", reconhecendo as intenções dessas pessoas, numa atitude de respeito e acolhimento; II - identificar, durante as visitas domiciliares, hipertensos e/ou diabéticos que expressem dificuldades na adesão ao tratamento, partilhando os casos com a equipe, identificando faltosos e organizando a agenda de retorno; III - estimular a participação ativa dos familiares ante os cuidados necessários, corresponsabilizando-os pela adesão ao plano terapêutico de seus entes; IV - organizar grupos com a participação dos demais membros da equipe e com a ajuda da comunidade, para fortalecer o suporte a hipertensos e diabéticos. (Síntese do Painel "Desafios e possibilidades na negociação do plano terapêutico com hipertensos e diabéticos" - Coletivo de ACS de Pacoti)

Como observado, a dificuldade quanto à mudança no estilo de vida e aceitação das limitações atreladas ao processo de adoecimento, ligada à fragilidade da rede social de apoio dessas pessoas acometidas por agravos crônicos, é reconhecida pelos ACSs como um grande desafio a ser encarado pelas equipes de Saúde da Família. Segundo Carvalho e $\mathrm{Ceccim}^{28}$, a possibilidade de alterar padrões e modelos causa medo, desconforto e movimentos de resistência. Faz-se preciso, então, negociar, argumentar, dialogar, em vez de impor sumariamente padrões e prescrições raramente acatados e incorporados à vida das pessoas. É necessário existir uma implicação dialética entre a denúncia de situações desumanizantes e o anúncio de sua superação ${ }^{12}$.

Por isso, em razão de um sem-número de problemas enfrentados pelos usuários com hipertensão e diabetes, acompanhados pelas equipes de Saúde da Família, minimamente, deve-se ter respeito às pessoas acompanhadas e cuidadas, pautando-se no fomento à autonomia e à dignidade humana.

Nessa perspectiva, determinados fatores ratificam esse fomento à autonomia e à dignidade humana. Entre estes, os ACSs apontam a necessidade de "compreender", antes mesmo de "orientar", ampliar a abordagem familiar, reorganizar o processo de trabalho, potencializando a corresponsabilidade entre os sujeitos e a formação de grupos que favoreçam o fortalecimento da rede social de apoio. Todos esses elementos foram expostos por eles como possibilidades pertinentes ao campo de atuação da Saúde da Família.

A escuta ativa, descrita por Freire ${ }^{12}$ como a disponibilidade permanente por parte do sujeito para a abertura à fala, ao gesto e às diferenças do outro, é ferramenta-chave para estabelecer vínculos efetivos e para a negociação terapêutica, tão essencial entre profissionais de saúde e indivíduos em situações de adoecimento crônico. Para o trabalho "com" as pessoas se requer a instalação de um diálogo permanente, sendo então a dialogicidade um potente instrumento para que os sujeitos aprendam e cresçam na diferença. 
Nesse processo de construção coletiva, segundo se identificou, os ACSs almejavam uma atuação mais integral, sobretudo em face da dinâmica familiar e comunitária, em detrimento de um olhar estritamente biologicista. Esse aspecto configura campo fértil para novas maneiras de produção de cuidados, delineando possibilidades de ruptura com lógicas hegemônicas "medicalizantes", as quais ainda persistem em disputar o ordenamento do processo de trabalho na Saúde da Família.

\section{Considerações finais}

A vivência de uma formação com ACSs, alicerçada na práxis da Educação Popular e Saúde, mostrouse estratégia político-pedagógica em consonância com o que se pretende alcançar com a Política de Educação Permanente no contexto da Saúde da Família. Ademais, propiciou condições objetivas de aprendizado significativo, baseadas em discussões coletivas e processos reflexivos de situações concretas emergentes do cotidiano de trabalho.

Reconhecer a fortaleza do encontro, valorizar as trocas de experiências, ampliar a análise crítica dos fatos, sentir-se sujeito do processo de transformação da realidade, permitir-se colocar em pauta situações desafiadoras e dispor-se a delinear propostas de luta e enfrentamento foram algumas das potencialidades evidenciadas por meio da sistematização do processo formativo partilhado.

O poder decisório dos ACSs na escolha dos problemas trabalhados nas oficinas, além do desvelamento de desafios comuns e possibilidades de superação construídas entre os pares, foram aspectos que favoreceram a desestabilização de um conhecimento tido como consolidado do modo de entendimento, de atuação, de produção de cuidados e das interações estabelecidas no cotidiano. Essa proposta de modos operandi permite romper com uma lógica hegemônica alienadora e convida os sujeitos a se arriscarem em novas maneiras de produzir saúde.

Esse convite à reconstrução de saberes e práticas no contexto da Saúde da Família se deu com o uso de múltiplas linguagens e com o incentivo à criatividade dos participantes em suas diferentes formas de expressão - dinâmicas, dramatizações, elaboração de textos-síntese, dentre outras.

Cabe destacar, também: esse percurso se tornou possível em razão da escolha pela pesquisa-ação, a qual tem a capacidade de identificar situações-problema latentes do contexto de estudo para o desencadeamento de propostas de pesquisas aplicadas que se façam relevantes, tanto para os sujeitos envolvidos quanto para cenários diversos onde se verifiquem desafios semelhantes.

Fica, pois, o convite à elaboração de mais estudos que apliquem os referenciais aqui citados em outros cenários de prática, utilizando-os como potenciais ferramentas de transformação da realidade. Além disso, é recomendável a produção de ensaios analíticos sobre o impacto de processos pedagógicos como o socializado nesse recorte. Neles poder-se-á avaliar se ocorreram mudanças significativas na forma de atuação do ACS junto às famílias acompanhadas, ou se foi possível potencializar seu trabalho como educador popular, como incentivador da organização e participação comunitária, enfim, um sujeito eminentemente "promotor de saúde".

É premente o reconhecimento do ACS como "sujeito de escolha", "sujeito da história", que, ao escolher como bandeiras de luta a saúde, como direito, e a concretude do verdadeiramente proposto na Estratégia Saúde da Família, percebe não ser possível aceitar uma adaptação ao saber hegemônico cartesiano, biologicista e reducionista. É preciso, então, inserir-se numa luta cotidiana para não ser objeto nem objetificar seus semelhantes, porquanto o compromisso consigo e com a humanidade exige responsabilidade e liberdade, em contraposição à pseudoneutralidade e ao determinismo daquele que, ao deter o poder equivocadamente, ainda insiste em querer naturalizar tal ação. 


\section{Colaboradores}

Os autores participaram, igualmente, de todas as etapas de elaboração do artigo.

\section{Referências}

1. Paim JS. Modelos de atenção e vigilância da saúde. In: Rouquayrol MZ, Almeida-Filho N, organizadores. Epidemiologia \& Saúde. 6a ed. Rio de Janeiro: Medsi; 2003. p. 567-71.

2. Ministério da Saúde. Secretaria de Atenção à Saúde. Departamento de Atenção Básica. Política Nacional de Atenção Básica [Internet]. Brasília (DF): MS/SAS/DAB; 2012 [acesso 2013 Dez 10]. Disponível em: http://189.28.128.100/dab/docs/publicacoes/geral/pnab.pdf

3. Matumoto S, Fortuna CM, Mishima SM, Pereira MJB, Domingos NAM. Supervisão de equipes no Programa de Saúde da Família: reflexões acerca do desafio da produção de cuidados. Interface (Botucatu). 2005; 9(16):9-24.

4. Malfitano APS, Lopes RE. Educação popular, ações em saúde, demandas e intervenções sociais: o papel dos agentes comunitários de saúde. Cad CEDES. 2009; 29(79):361-72.

5. Ávila MMM. Avaliação da formação técnica do agente comunitário de saúde no Ceará. Fortaleza: Centro de Ciências da Saúde da Universidade Estadual do Ceará; 2010.

6. Pedrosa JIS. A educação popular e a formação dos trabalhadores de nível médio da saúde. Trab Educ Saude. 2007; 5(1):125-38.

7. Bachilli RG, Scavassa AJ, Spiri WC. A identidade do agente comunitário de saúde: uma abordagem fenomenológica. Cienc Saude Colet. 2008; 13(1):51-60.

8. Nunes MO, Trad LB, Almeida BA, Homem CR, Melo MCIC. O agente comunitário de saúde: construção da identidade desse personagem híbrido e polifônico. Cad Saude Publica. 2002; 18(6):1639-46.

9. Vasconcelos EM. Educação popular: instrumento de gestão participativa dos serviços de saúde. In: Ministério da Saúde, Secretaria de Gestão Estratégica e Participativa, Departamento de Apoio à Gestão Participativa. Caderno de educação popular e saúde. Brasília (DF): MS/SGEP/DAGEP; 2007. p. 18-29.

10. Albuquerque $P C$, Stotz EN. A educação popular na atenção básica à saúde no município: em busca da integralidade. Interface (Botucatu). 2004; 8(15):259-74.

11. Freire P. Pedagogia do oprimido. 54a ed. Rio de Janeiro: Paz e Terra; 2013.

12. Freire P. Pedagogia da autonomia: saberes necessários à prática educativa. $43 a$ ed. São Paulo: Paz e Terra; 2011

13. Paim JS. Reforma sanitária brasileira: contribuição para a compreensão e crítica. Salvador: EdUFBA; 2008.

14. Carvalho MAP, Acioli S, Stotz EN. O processo de construção compartilhada do conhecimento: uma experiência de investigação científica do ponto de vista popular. In: Vasconcelos EM, organizador. A saúde nas palavras e nos gestos: reflexões da rede Educação Popular e Saúde. São Paulo: Hucitec; 2001. p. 101-14.

15. Carvalho MAP. Construção compartilhada do conhecimento: análise da produção de material educativo. In: Ministério da Saúde. Secretaria de Gestão Estratégica e Participativa. Departamento de Apoio à Gestão Participativa. Caderno de educação popular e saúde. Brasília (DF): MS/SGEP/DAGEP; 2007. p. 91-101.

16. Pedrosa JIS. Educação popular, saúde, institucionalização: temas para debate. Interface (Botucatu). 2001; 5(8):137-8.

17. Secretaria de Saúde do Estado do Ceará. Plano Diretor de Regionalização. [Internet]. Fortaleza: SESA; 2006 [acesso 2013 Dez 10]. Disponível em: http://portal.saude.gov.br/ portal/arquivos/pdf/pdr_2006_ce.pdf 
18. Ministério da Saúde. Sala de apoio à gestão estratégica [Internet]. Brasília (DF): MS; 2013 [acesso 2013 Dez 10]. Disponível em: http://189.28.128.178/sage/

19. Barbier R. A pesquisa-ação. Brasília (DF): Líber Livro Editora; 2007.

20. Fernandes MCP, Backes VMS. Educação em saúde: perspectivas de uma equipe da Estratégia Saúde da Família sob a óptica de Paulo Freire. Rev Bras Enferm. 2010; 63(4):567-73.

21. Damasceno AM, Said FA. O método problematizador no cuidado educativo com mulheres no preparo ao parto. Cogitare Enferm [Internet] 2008 [acesso 2013 Dez 10]; 13(2):173-83.

Disponível em: http://ojs.c3sl.ufpr.br/ojs2/index.php/cogitare/article/viewFile/12433/8548

22. Lefevre F, Lefevre AMC. O sujeito coletivo que fala. Interface (Botucatu). 2006; 10(20):517-24.

23. Pedrosa JIS. Perspectivas na avaliação em promoção da saúde: uma abordagem institucional. Cienc Saude Colet. 2004; 9(3):617-26.

24. Ministério da Saúde. Secretaria de Vigilância em Saúde. Secretaria de Atenção à Saúde. Política Nacional de Promoção da Saúde [Internet]. 3a ed. Brasília (DF): MS/SVS/SAS; 2010 [acesso 2013 Dez 10]. Disponível em: http://bvsms.saude.gov.br/bvs/publicacoes/ politica_nacional_promocao_saude_3ed.pdf

25. Ministério da Saúde. Secretaria de Políticas de Saúde. Projeto Promoção da Saúde. As cartas da Promoção da Saúde [Internet]. Brasília (DF): MS/SPS; 2002 [acesso 2013 Dez 10]. Disponível em: http://bvsms.saude.gov.br/bvs/publicacoes/cartas_promocao.pdf

26. Czeresnia D. O conceito de saúde e a diferença entre prevenção e promoção. In: Czeresnia D, Freitas CM, organizadores. Promoção da Saúde: conceitos, reflexões, tendências. 2a ed. Rio de Janeiro: Fiocruz; 2009. p. 43-57.

27. Freitas $C M$. A vigilância da saúde para a promoção da saúde. In: Czeresnia D, Freitas $C M$, organizadores. Promoção da Saúde: conceitos, reflexões, tendências. 2a ed. Rio de Janeiro: Fiocruz; 2009. p. 145-64.

28. Carvalho YM, Ceccim RB. Formação e educação em saúde: aprendizados com a Saúde Coletiva. In: Campos GWS, Bonfim JRA, Minayo MCS, Akerman M, Drumond-Júnior M, Carvalho YM, organizadores. Tratado de Saúde Coletiva. 2a ed. São Paulo: Hucitec; 2012. p. 137-70.

Queiroz DM, Silva MRF, Oliveira LC. Educación permanente con Agentes Comunitarios de Salud: potencialidades de una formación regida por el factor de referencia de la Educación Popular y Salud. Interface (Botucatu). 2014;18 Supl 2:1199-1210.

En la Salud de la Familia, el agente comunitario de salud (ACS) es portavoz del modelo de atención implementado; no obstante, recibe capacitaciones incipientes y es necesario que la educación permanente cierre gradualmente brechas identificadas en su cotidiano de trabajo. El objetivo fue indicar los pasos del proceso pedagógico vivido con los ACS en el municipio de Pacoti, Ceará, Brazil, propuesta de modus operandi de una formación basada en el factor de referencia de la Educación Popular y Salud (EPS). Se trata de una investigación-acción con 24 ACS. Se promovieron ocho talleres de construcción compartida del conocimiento. Desde la elección de los temas a la revelación de desafíos comunes y propuestas de superación, causando la desestabilización de conocimientos consolidados, quedó claro el poder de la EPS para romper con una lógica hegemónica enajenante, instigando a los sujetos a que se arriesguen en nuevas formas de producir salud.

Palabras-clave: Agentes Comunitarios de Salud. Formación de recursos humanos. Salud de la Familia. Educación Popular. Educación permanente. 